\title{
GOMMENTARY
}

\section{Promoting Active Learning in Residency Didactic Sessions}

Todd Zakrajsek, PhD; Warren Newton, MD, MPH

(Fam Med. 2021;53(7):608-10.)

doi: 10.22454/FamMed.2021.894932

Published Online First May 26, 2021

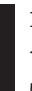

$\mathrm{n}$ the early $1990 \mathrm{~s}$, a revolution began in the American higher educational system. The time had come to change the focus of education from teaching to learning. ${ }^{1}$ Instead of focusing on what was covered in a didactic session, such as grand rounds, a call emerged to shift the focus instead to the extent that learners actually learned. In theory, this shift would have been readily accepted by educators as a logical direction to pursue. In practice, however, moving educational practices in this direction has been an exceedingly difficult challenge. Changing practice is never easy. To move from teaching to learning, educators must think about teaching in a different way. This shift means moving from traditional lectures of content-laden material to instructional methods designed to draw learners directly into their own learning, and difficulty has been increased by the ubiquity of PowerPoint software. Succinctly stated by King in 1993, it involves moving "from sage on the stage to guide on the side."

In the early 1990s, this new approach to focus on learner engagement was named "active learning." The credit for launching the term is most often attributed to Bonwell and Eison. ${ }^{3}$ In their groundbreaking book, they defined active learning as "anything that involves the students in doing things and thinking about the things they are doing." Note the inclusion of two aspects of active learning: students "doing things" (eg, preparing for the learning session, participating in discussion with other learners, taking notes) and "thinking about things they are doing" (eg, reflection, classroom assessments). It is important to note that active learning pertains to all forms of learning: precepting, small group teaching, and large-group didactics. An educational experience is active based on what happens with the learner, not the number of learners present.

Although the active learning movement began 30 years ago, many family medicine residencies have not fully embraced this instructional approach. One reason may well be that our language runs counter to the concept of active learning. For example, in medical education, the word "didactic" is often synonymous with all formal teaching. The Oxford Advanced Learner's Dictionary defines "didactic" as "telling people things rather than letting them find out for themselves." A system of education whereby learners are "told" is efficient when it works. Unfortunately, studies over the past 25 years have consistently shown that extended lectures are not an effective instructional strategy. ${ }^{4-6}$ Although efforts to improve education in family medicine have often included statements like "family medicine should devise effective methods to teach community medicine..." there is often a lack of information about the process by which that should happen.

Making a major shift in the way we teach is no small feat. At this time, however, an ever-increasing body of work clearly and consistently documents active learning effectiveness over traditional lecture through the use of an increasing number of supporting teaching

From the University of North Carolina - Chapel Hill (Drs Zakrajsek and Newton); and the American Board of Family Medicine, Lexington, KY (Dr Newton). 
strategies and educational technology solutions. ${ }^{8}$ Within family medicine, recent studies have similarly highlighted the effectiveness and use of active learning in both undergraduate $^{9,10}$ and graduate medical education settings. ${ }^{11}$

In preparation for the family medicine residency summit, the American Board of Family Medicine conducted a national survey of both residency faculty and residents about how residency conferences are taught. ${ }^{12}$ The results paint a mixed picture. Didactic sessions represent a substantial commitment of time; over $86 \%$ of residency faculty and residents report over 4 hours of formal conferences per week, with $72 \%$ of residency faculty reporting that, during the pandemic, the didactic curriculum was unchanged and an extra $22 \%$ reporting only a slight decrease in time. Attendance is variable, however, with $21 \%$ of residents reporting attending less than half of the conferences and only about $50 \%$ of residents reporting attending more than $75 \%$ of the conferences.

Over $80 \%$ of residents report having required prereading or material to review in advance in less than 25\% of conferences. Fifty-two percent of residents report that over half of the sessions used interactive techniques such as case discussion, polling, or other techniques. Faculty and resident estimates of the need for preparation and the use of interactive learning was similar: there is clearly substantial room for improvement in making learning more likely to be effective. Residents also report significant amounts of personal teaching, with $63 \%$ of the national sample having taught at least one session in the 3 months prior to the survey, but only $29 \%$ report formal training in teaching. The culture of "see one, do one, teach one" is alive and well: without being taught evidence-based strategies for effective teaching, many residents will likely anchor their teaching strategies in how they were taught, which often does not include active learning strategies. These results need to be considered in the context of the methodology that is described on the website. Of faculty interested in contributing to the project of reenvisioning the future of residency education, 543 faculty ( $65.1 \%$ response rate), and 301 residents (50.4\% response rate) responded. In addition, the survey took place in the fall of 2020 , when there was ongoing impact of the COVID-19 pandemic on resident clinical care and schedules.

\section{A Way Forward}

Whither active learning in residency didactic sessions? Of course, residencies are on-the-job training, in which the majority of learning is by doing, using an apprenticeship and smallteam teaching model. This emphasis is as it should be, and is codified by residency standards that acknowledge that clinical emergencies take precedence over formal didactics. Educationally, however, we believe that didactic sessions are an important part of the residency curriculum. They represent a substantial commitment of time for both faculty and residents. They support key components of education (knowledge retrieval, interleaving, and spaced repetition ${ }^{13-15}$ ), which modern educational research underscores are critical in learning. How we teach them is thus a key component of the strategy for renewing family medicine residency education.

We look forward to more research on how best to support learning in residency didactic sessions. In the meantime, however, a primary question is how much? Four to 6 hours per week is current typical practice, amounting to a half day per week or a little more. Is this the right amount? Is attendance required? How often should clinical emergencies get in the way, and is charting an emergency? A parallel question is whether to organize conferences in focused academic half days or distributed across the week. Both have a good rationale, depending on local geography and culture. Finally, in an age of hard limits to duty hours, are didactic sessions important enough to put in the morning, when almost all residents can attend, but when faculty need to cover clinical demands in the office and hospital?

As for pedagogy, we propose that all residency didactic sessions, both large and small sessions, on site or online, include active learning strategies, with assignment of carefully selected prework. These strategies must clearly include learners in "doing things and thinking about the things they are doing." This does not necessarily imply that lectures cease, but that active learning strategies be used to augment lectures. In addition, all didactic sessions should include strategies for assessing learning either during or at the end of the session. Assessments should be more than resident satisfaction; evaluations should attempt to capture gaps in knowledge and practice and specific intended clinical practice changes. Active learning strategies may result in less content being covered by the teacher in a lecture format, but 
should not result in less learning. The principle is that assessment drives learning.

Active learning strategies should always include research-based aspects of how humans learn, be it problem-based learning, smallgroup discussion, simulations, or lectures. The field of human learning and memory is a complex area of specialization, and research continues to reveal important factors associated with areas such as brain-based learning, the impact of individual life experiences and culture on learning, and educational technologies. ${ }^{16}$ Additionally, there are universally accepted aspects of learning described by educational psychologists and others that have promise to improve family medicine residency teaching immediately. A few examples of learning components that have received extensive research include encoding specificity, targeted feedback, activation of prior knowledge, reducing cognitive load, practice at recall, and developing metacognitive skills. ${ }^{16-17}$ Most importantly, these factors are typically independent of the type of learning, learner preferences, whether the learning is skills-based or factual, and whether the learner is in a classroom or walking down the street.

We also recommend that all residents get training in teaching. As all of us appreciate, the etymology of "doctor" is "teacher," and teaching, whether of patients, peers, other professionals or community members, is a key aspect of our traditional role. When and how best to train teaching is ripe for innovation and dialogue in the specialty, but it seems clear that it will be helpful for faculty development to develop evidence-based curricula in teaching for residents. The specialty has a significant opportunity to improve the teaching that young physicians give both formally and informally throughout their careers.

In conclusion, it seems clear that the revision of family medicine residencies will incorporate a major emphasis on competency-based education. We endorse the emphasis on competencies and outcomes with enthusiasm. But we also believe that how we teach is important, and that formal didactic conferences can play a critical role in residency education. Rethinking how we teach, drawing on the extensive research related to human learning, is critical to reenvisioning family medicine residency education.
CORRESPONDING AUTHOR: Address correspondence to Dr Warren Newton, American Board of Family Medicine, 1648 McGrathiana Parkway, Lexington, KY 40511. 919604-2041.wnewton@theabfm.org.

\section{References}

1. Barr RB, Tagg J. From teaching to learning — a new paradigm for undergraduate ducation. Change. 1995;27(6):12-26. doi:10.1080/00091383.1995.10544672

2. King A. From sage on the stage to guide on the side. Coll Teach. 1993;41(1):30-35. doi:10.1080/87567555.1993.9926781

3. Bonwell C, Eison J. Active Learning: creating excitement in the classroom. Information Analysis-ERIC Clearinghouse Products; 1991. http://files.eric.ed.gov/fulltext/ED336049.pdf/. Accessed July 14, 2018.

4. Freeman S, Eddy SL, McDonough M, et al. Active learning boosts performance in STEM courses. Proc Natl Acad Sci USA. 2014;111:8410-8415. doi:10.1073/pnas.1319030111

5. Hake R. Interactive-engagement vs. traditional methods: a six-thousand-student survey of mechanics test data for introductory physics courses. Am J Phys. 1998;66(1):64-74. doi: $10.1119 / 1.18809$

6. Deslauriers L, Schelew E, Wieman C. Improved learning in a large-enrollment physics class. Science. 2011;332(6031):862864. doi:10.1126/science. 1201783

7. Martin JC, Avant RF, Bowman MA, et al; Future of Family Medicine Project Leadership Committee. The Future of Family Medicine: a collaborative project of the family medicine community. Ann Fam Med. 2004;2(suppl 1):S3-S32. doi:10.1370/afm.130

8. Major CH, Harris M, Zakrajsek T. Teaching for Learning: 101 Intentionally Designed Educational Activities to Put Your Students on the Path to Success. New York, NY: Routledge; 2016.

9. Roshni M, Rahim A. Small group discussions as an effective teaching-learning methodology for learning the principles of family medicine among 2nd-year MBBS students. J Family Med Prim Care. 2020;9(5):2248-2252. doi:10.4103/jfmpc. jfmpc_1228_19

10. Everard KM, Schiel KZ. Learning outcomes from lecture and an online module in the family medicine clerkship. Fam Med. 2020;52(2):124-126. doi:10.22454/FamMed.2020.211690

11. Armson H, Wycliffe-Jones K, Mackay MP, Roder S. Academic half-days: facilitated small groups to promote interactive learning. Fam Med. 2020;52(1):53-64. doi:10.22454/ FamMed.2020.947981

12. Starfield Summit V: Re-Envisioning Family Medicine Education. https://residency.starfieldsummit.com/communitydialogue. Accessed March 10, 2021.

13. Raget D. Introduction to Chunks and Rules. https://www. w3.org/Data/demos/chunks/chunks.html. Accessed May 1, 2021.

14. Rohrer D. Interleaving helps students distinguish among similar concepts. Educ Psychol Rev. 2012;24(3):35-367. doi:10.1007/s10648-012-9201-3

15. Glen D. Close the book, recall, write it down. Chron High Educ. 2009;55(34):A1.

16. National Academies of Sciences, Engineering, and Medicine. How people learn II: learners, contexts, and cultures. Washington, DC: The National Academies Press; 2018.

17. Gluck MA, Mercado E, Myers C. Learning and memory: from brain to behavior. 4th ed. New York, NY: Worth Publishers; 2020 . 